Supplement of Biogeosciences, 11, 4459-4476, 2014

http://www.biogeosciences.net/11/4459/2014/

doi:10.5194/bg-11-4459-2014-supplement

(C) Author(s) 2014. CC Attribution 3.0 License.

(c) (1)

Supplement of

\title{
Methyl iodide production in the open ocean
}

I. Stemmler et al.

Correspondence to: I. Stemmler (irene.stemmler@zmaw.de) 


\section{Simulated and observed methyl iodide concentrations for individual ship cruises}
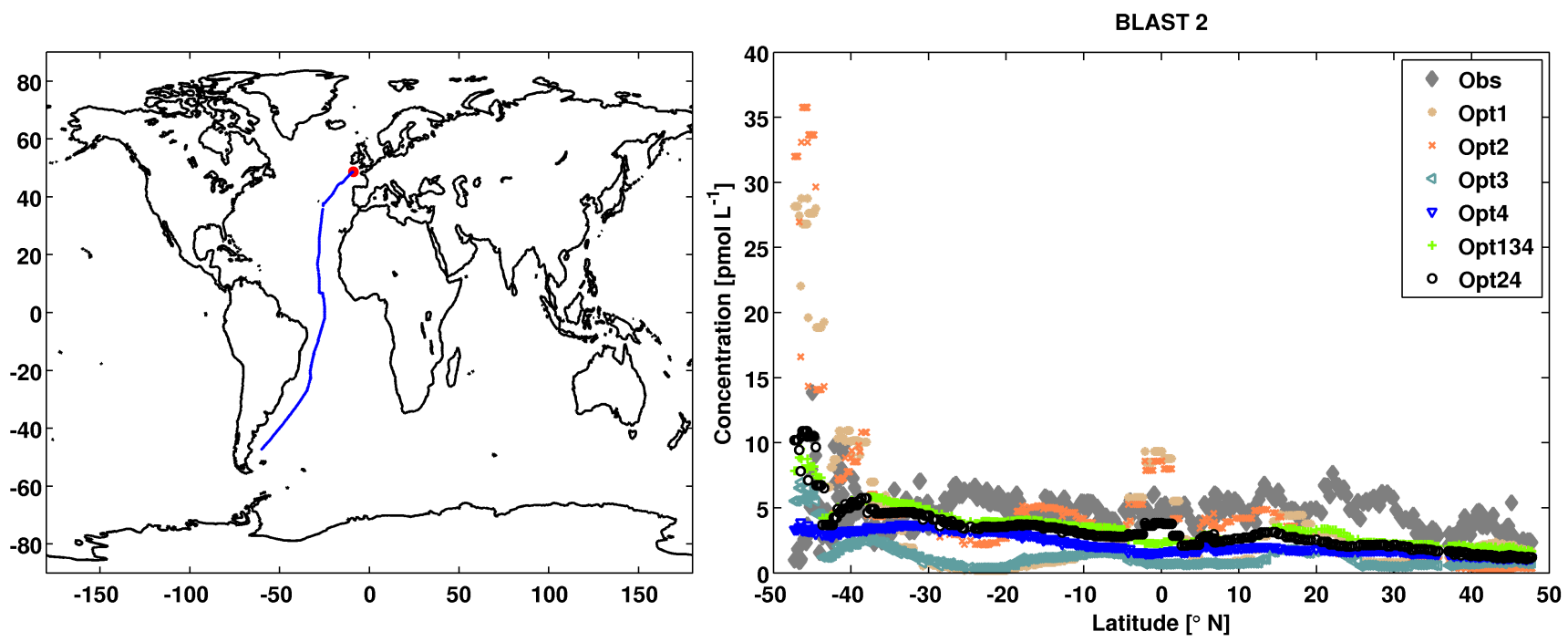

Figure S1 Observations are from the Polarstern cruise BLAST 2, 18.10.-21.11.1994 (Butler et al., 2007) as listed in the SI of (Ziska et al., 2013). Values are shown only where the model ocean is deeper than $200 \mathrm{~m}$.
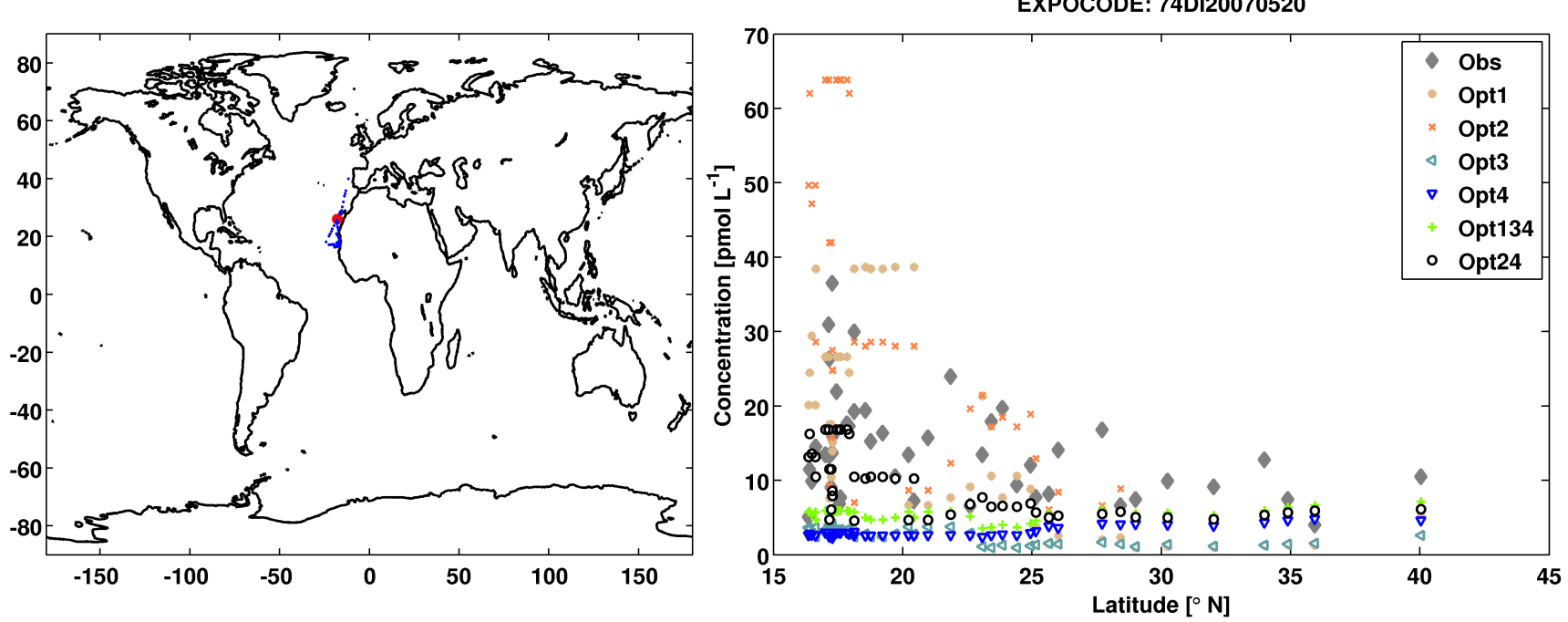

Figure S2 Observations are from a RSS Discovery cruise in May 2007 (EXPOCODE: 74DI20070520) (Jones et al., 2010) as listed in the SI of (Ziska et al., 2013). Values are shown only where the model ocean is deeper than $200 \mathrm{~m}$. 

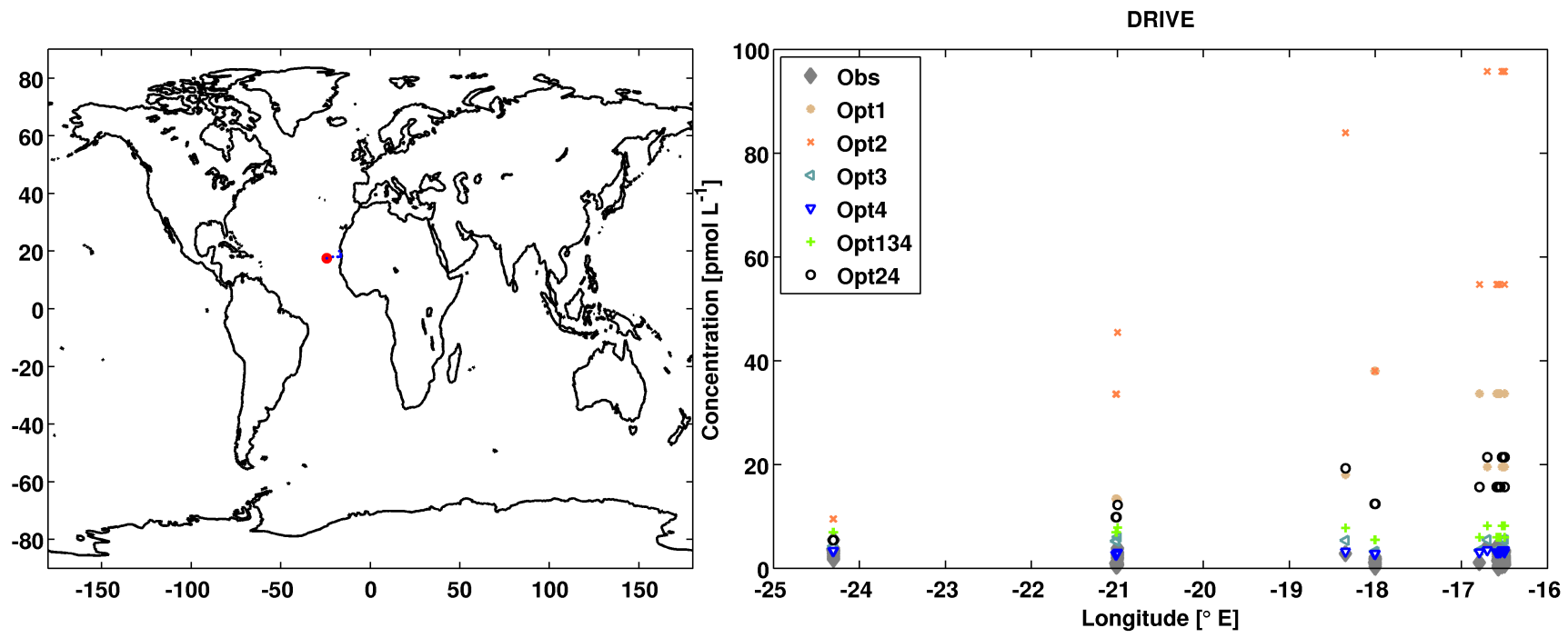

Figure S3 Observations are from the Poseidoin cruise DRIVE in June 2010 as listed in the SI of (Ziska et al., 2013). Values are shown only where the model ocean is deeper than $200 \mathrm{~m}$.
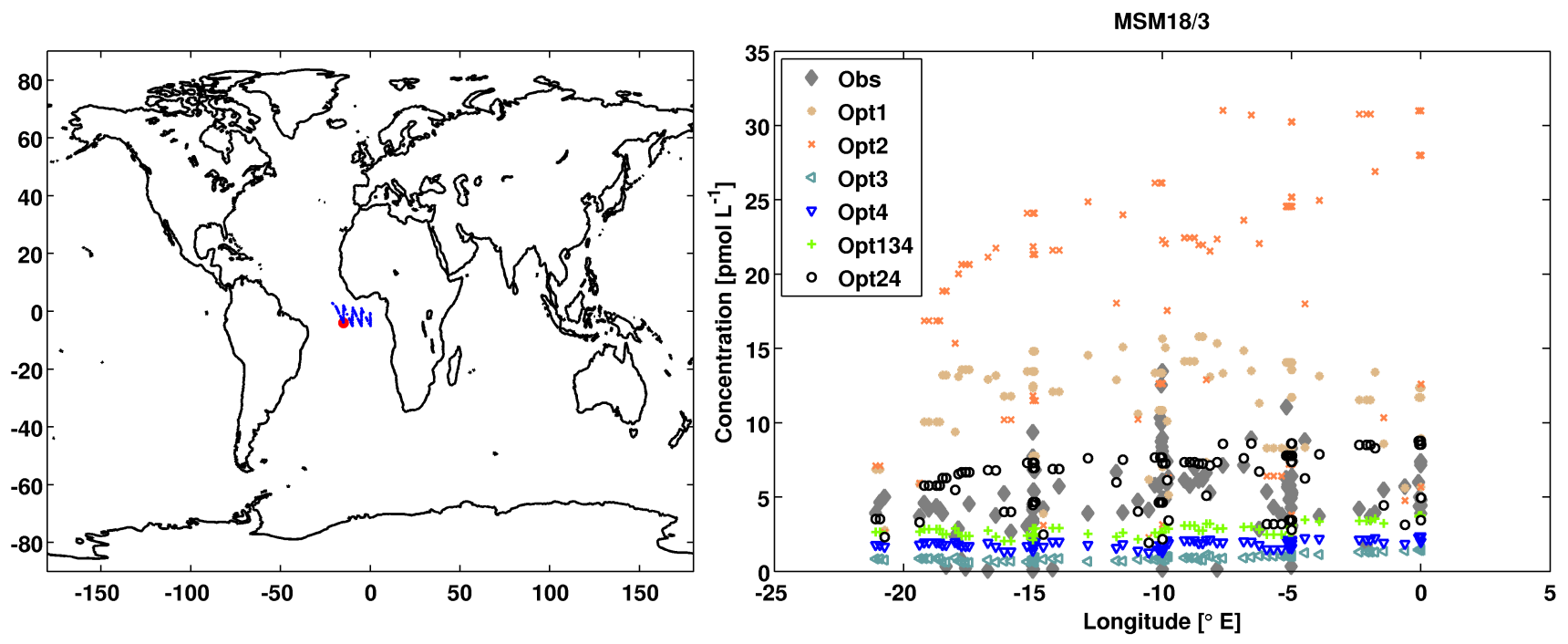

Figure S4 Observations are from the RV Maria S. Merian cruise MSM18/3 in June 2011 as listed in the SI of (Ziska et al., 2013). Values are shown only where the model ocean is deeper than $200 \mathrm{~m}$. 

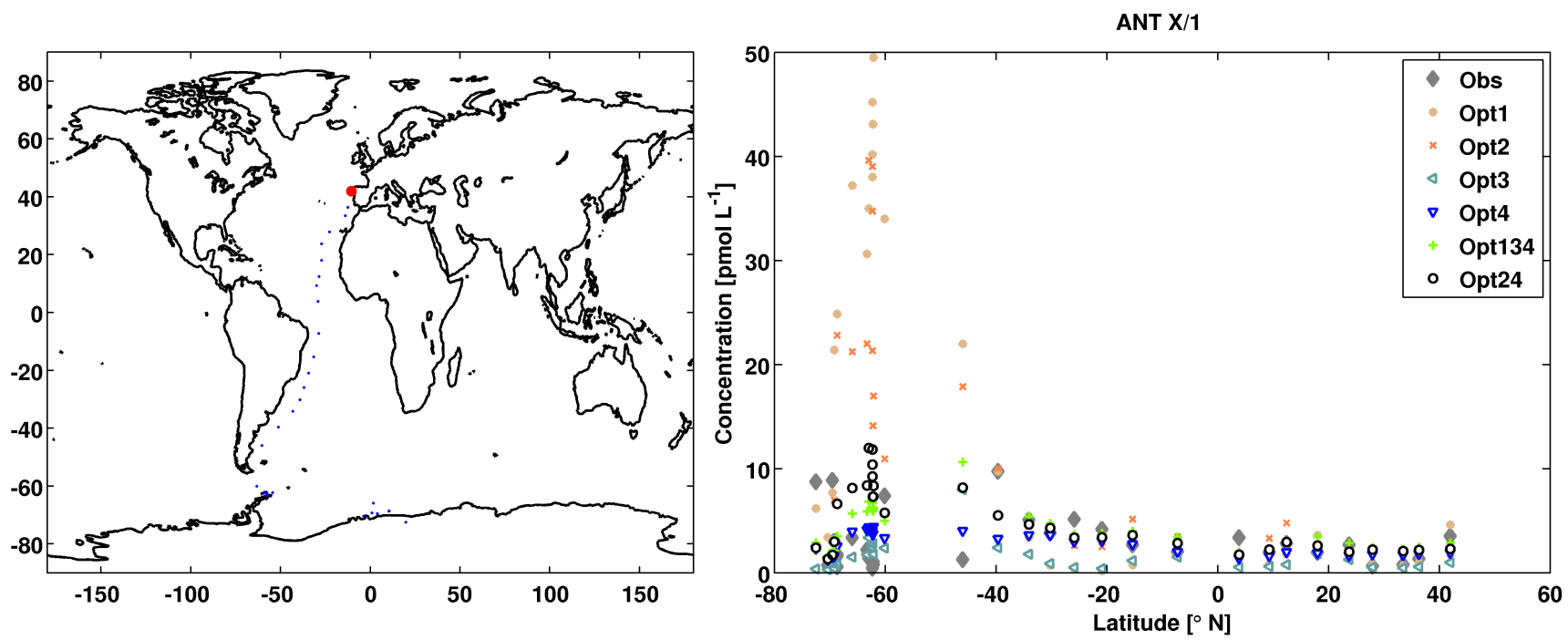

Figure S5 Observations are from the Polarstern cruise ANT X/1 in November 1994 (Schall et al., 1997) as listed in the SI of (Ziska et al., 2013). Values are shown only where the model ocean is deeper than $200 \mathrm{~m}$.
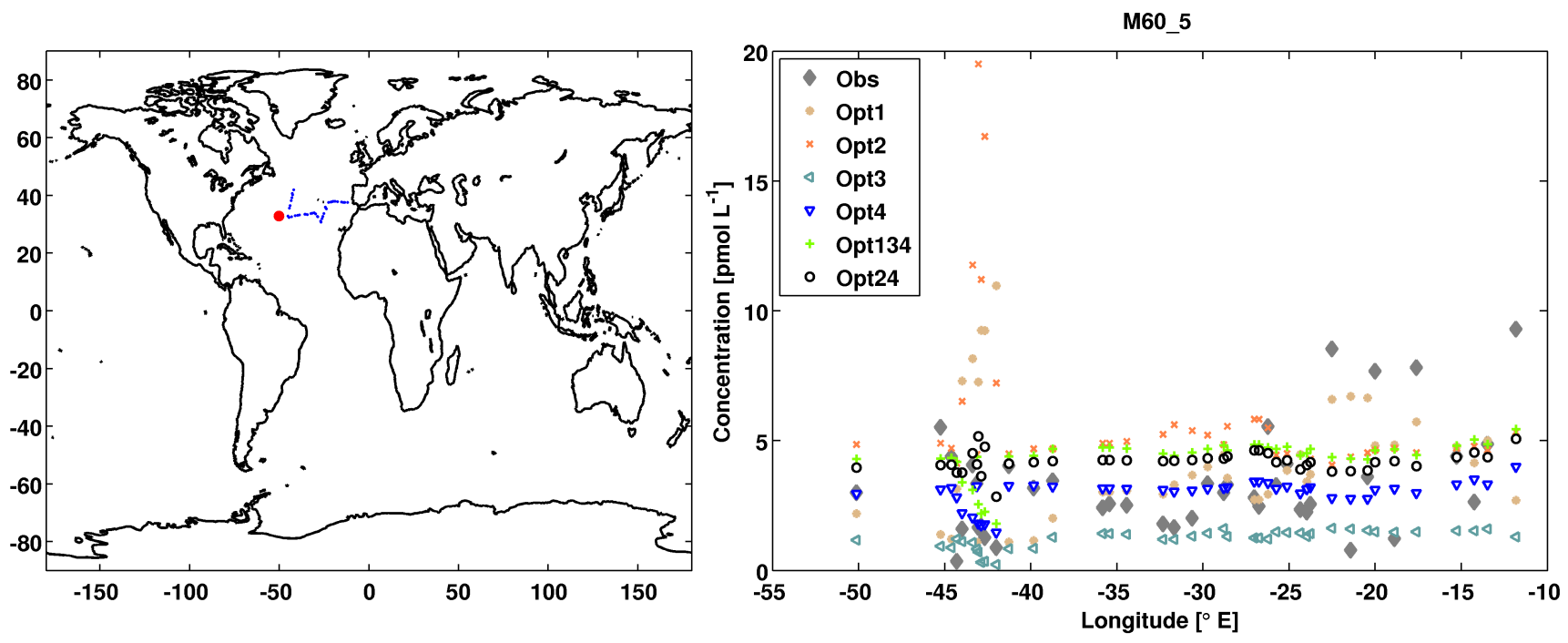

Figure S6 Observations are from the Meteor cruise M60_5, 09.03.-15.04.2004 as listed in the SI of (Ziska et al., 2013). Values are shown only where the model ocean is deeper than $200 \mathrm{~m}$. 

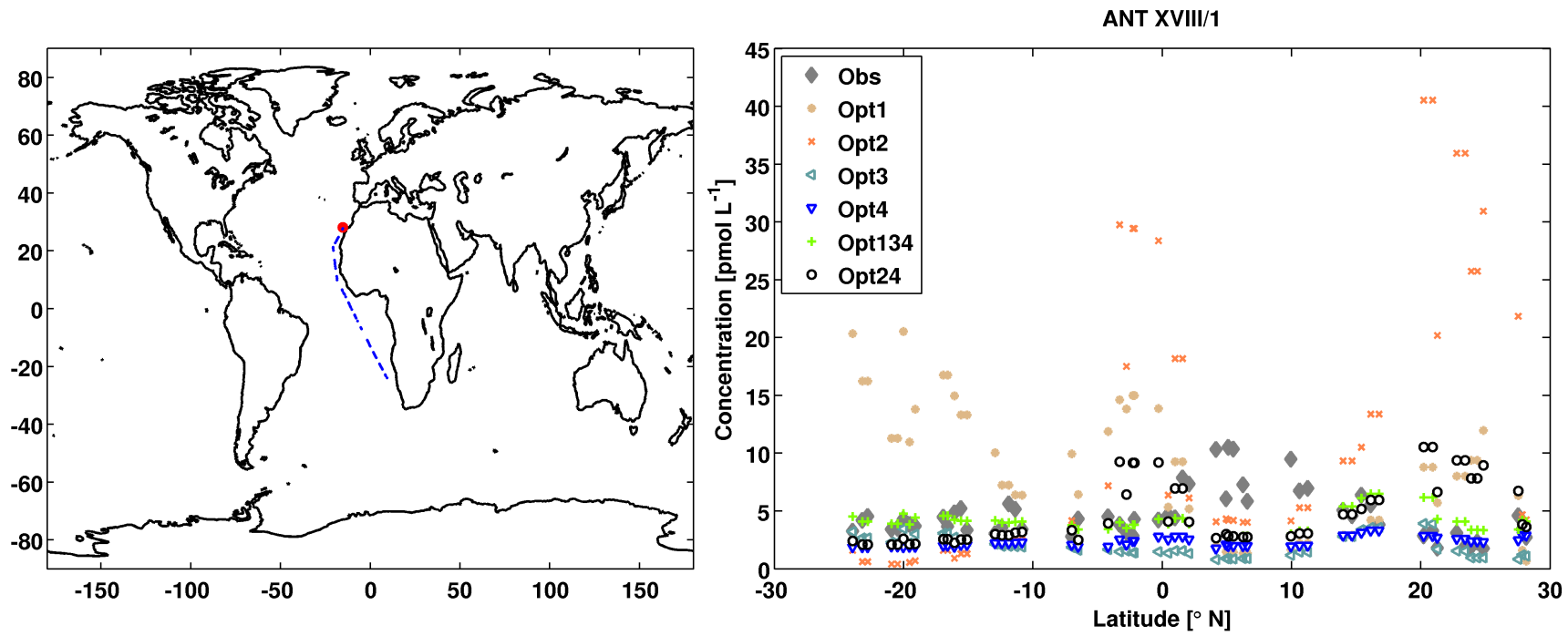

Figure S7 Observations are from the Polarstern cruise ANT XVIII/1 in August 2000 (Chuck et al., 2005) as listed in the SI of (Ziska et al., 2013). Values are shown only where the model ocean is deeper than $200 \mathrm{~m}$.
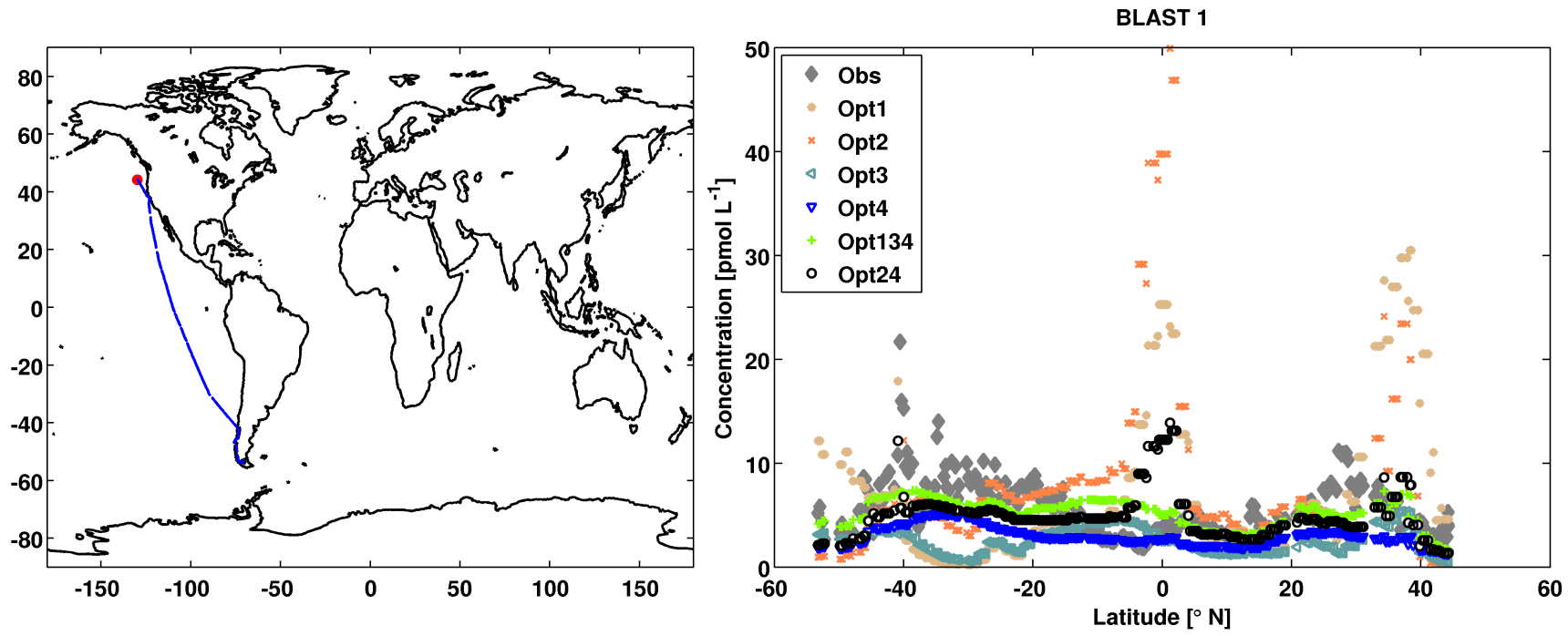

Figure S8 Observations are from the Discoverer cruise BLAST 1, 18.01.-17.02.1994 (Butler et al., 2007) as listed in the SI of (Ziska et al., 2013). Values are shown only where the model ocean is deeper than $200 \mathrm{~m}$. 

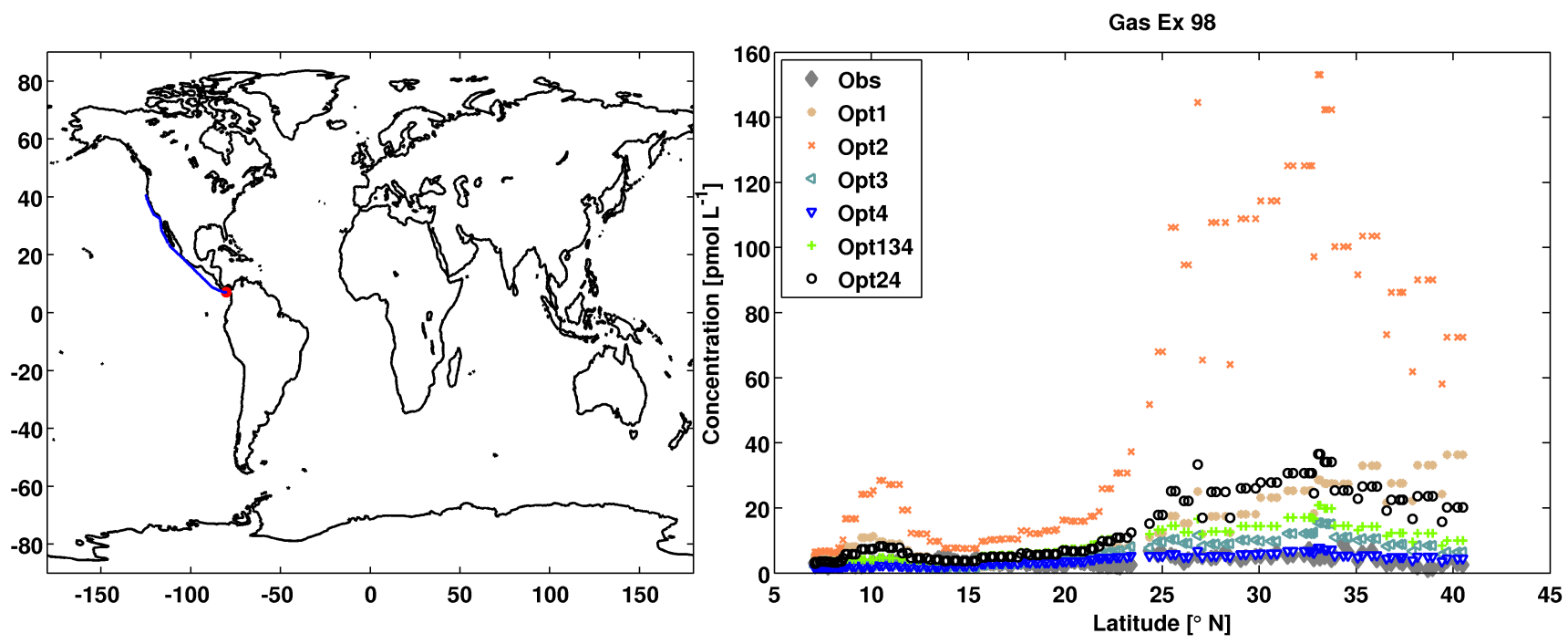

Figure S9 Observations are from the NOAA ship Ronald H. Brown cruise Gas Ex 98, 07.05.-27.07.1998 (Butler et al., 2007) as listed in the SI of (Ziska et al., 2013). Values are shown only where the model ocean is deeper than $200 \mathrm{~m}$.
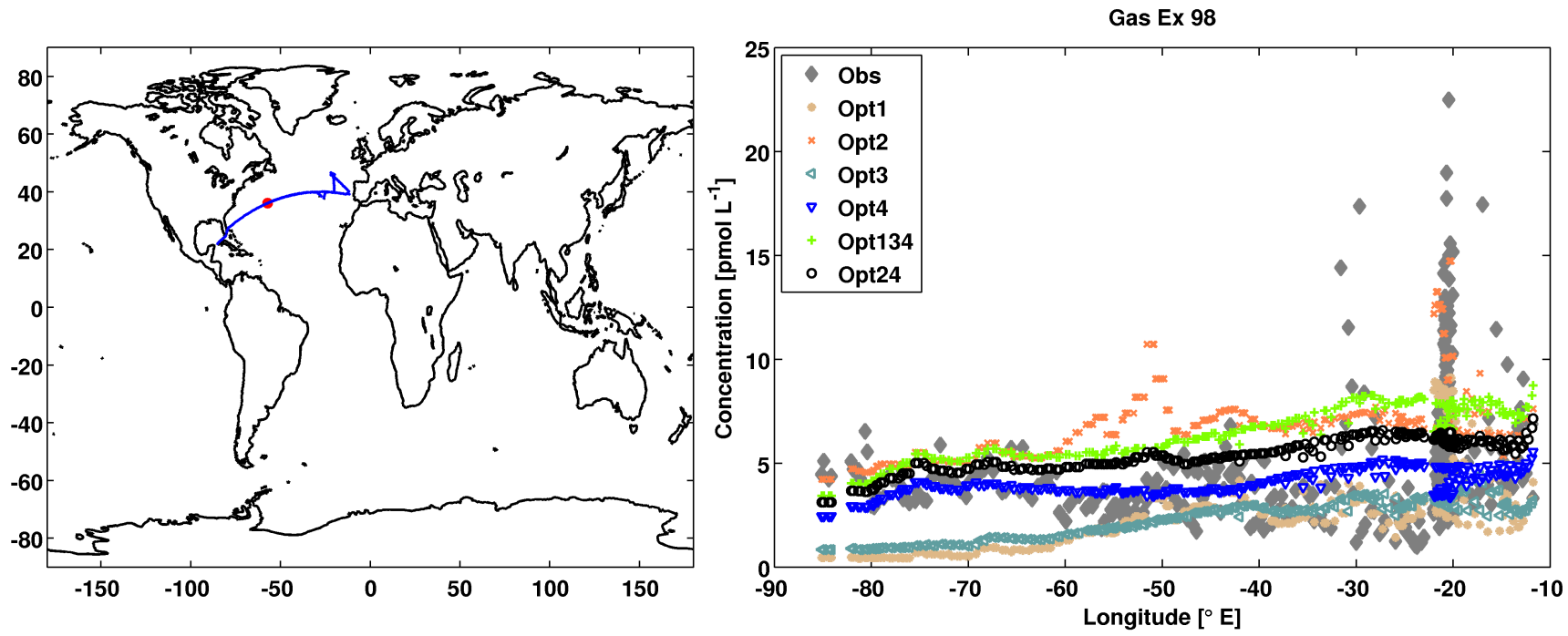

Figure S10 Observations are from the NOAA ship Ronald H. Brown cruise Gas Ex 98, 07.05.-27.07.1998 (Butler et al., 2007). Values are shown only where the model ocean is deeper than $200 \mathrm{~m}$. 

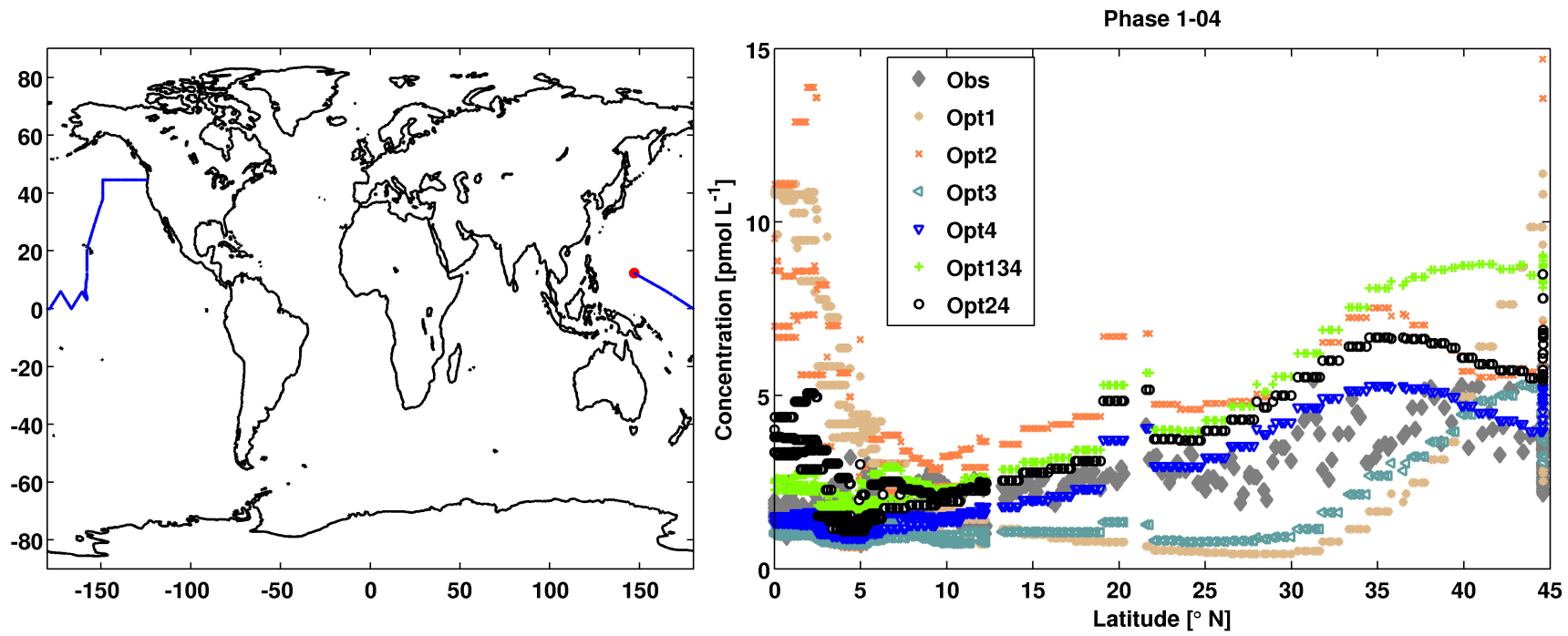

Figure S11 Observations are from the R/V Wecoma cruise Phase 1-04, 22.5.-02.07.2004 (Butler et al., 2007). Values are shown only where the model ocean is deeper than $200 \mathrm{~m}$.
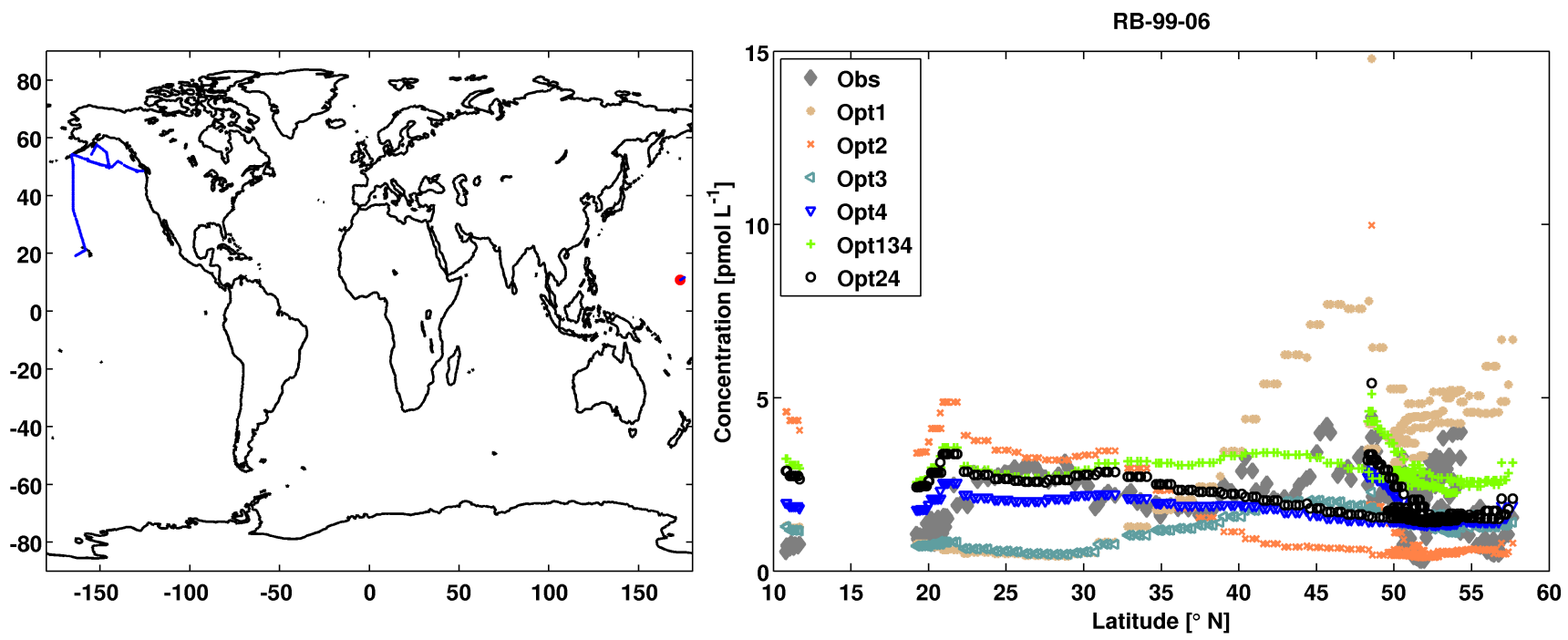

Figure S12 Observations are from the NOAA ship Ronald H. Brown cruise RB-99-06, 14.09.-23.10.1999 (Butler et al., 2007) as listed in the SI of (Ziska et al., 2013). Values are shown only where the model ocean is deeper than $200 \mathrm{~m}$. 

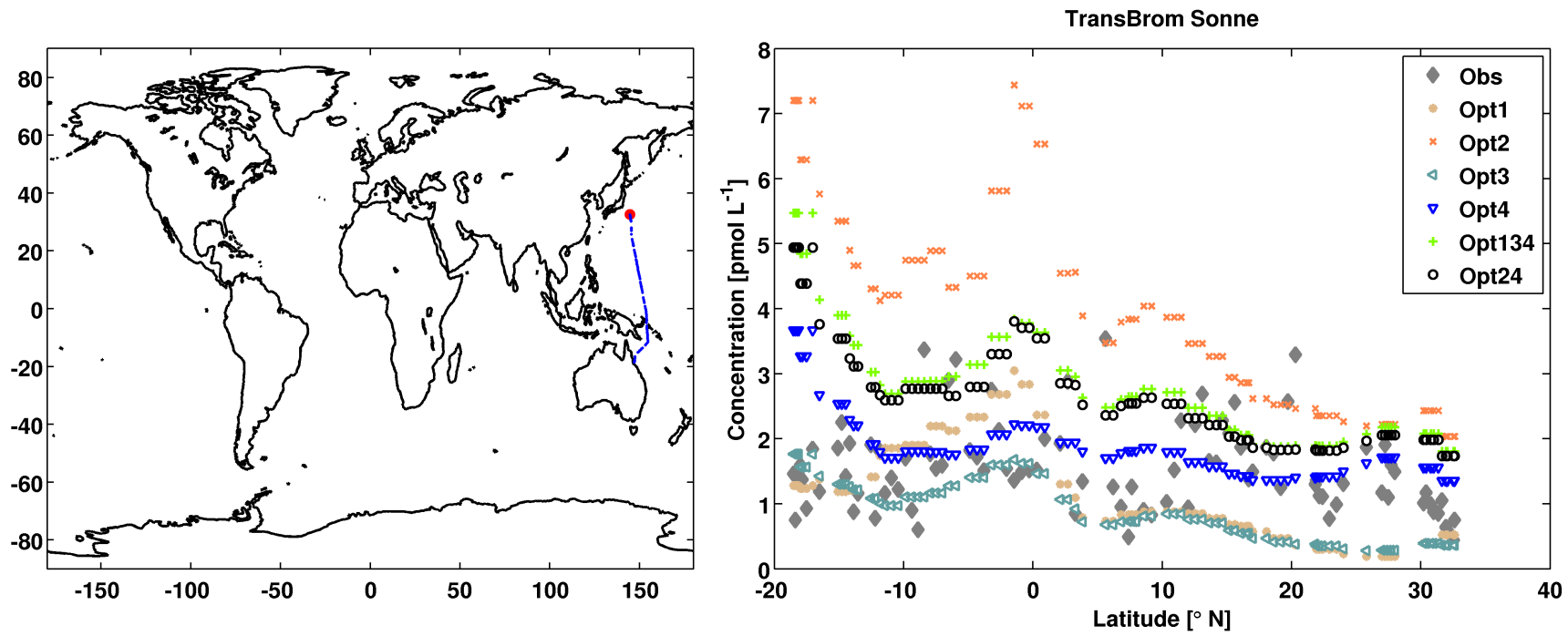

Figure S13 Observations are from the R/V Sonne cruise TransBrom Sonne in Oktober 2009 as listed in the SI of (Ziska et al., 2013). Values are shown only where the model ocean is deeper than $200 \mathrm{~m}$.
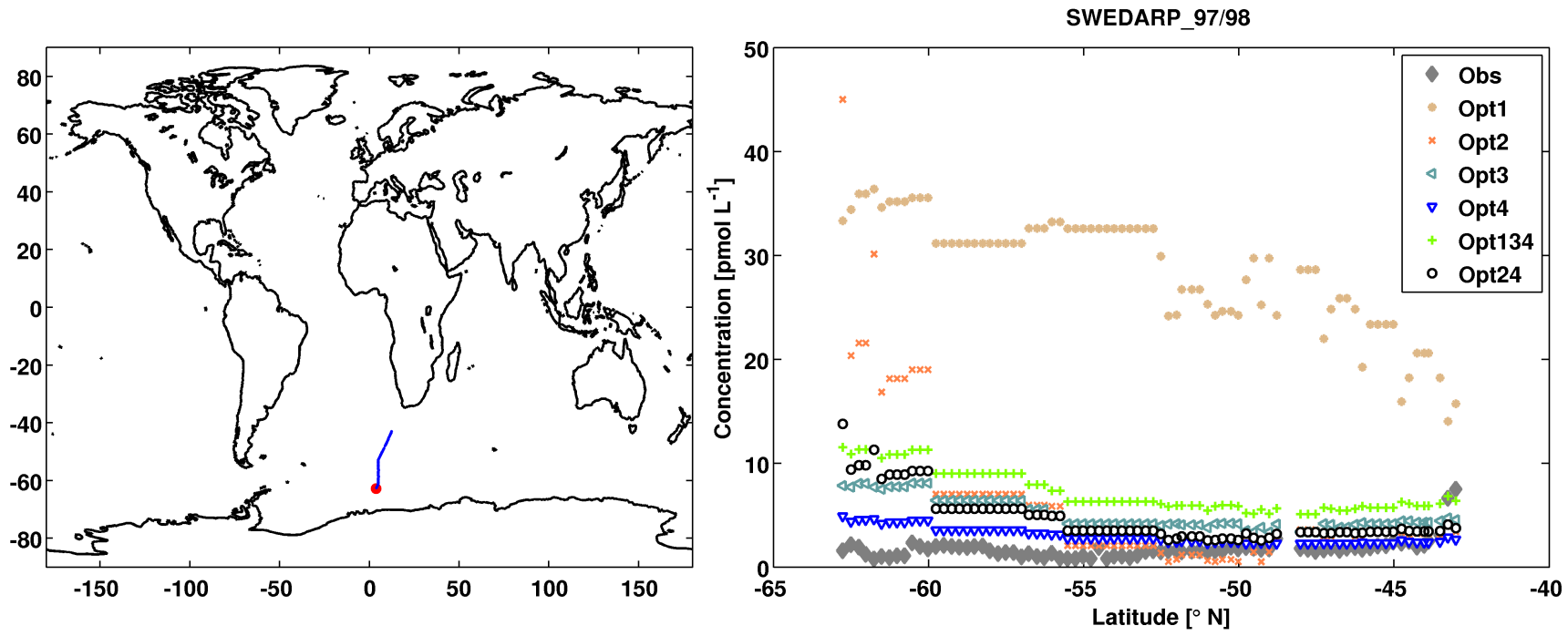

Figure S14 Observations are from the SA Agulhas cruise SWEDARP_97/98 in December 1997 (Abrahamsson et al., 2004) as listed in the SI of (Ziska et al., 2013). Values are shown only where the model ocean is deeper than $200 \mathrm{~m}$. 

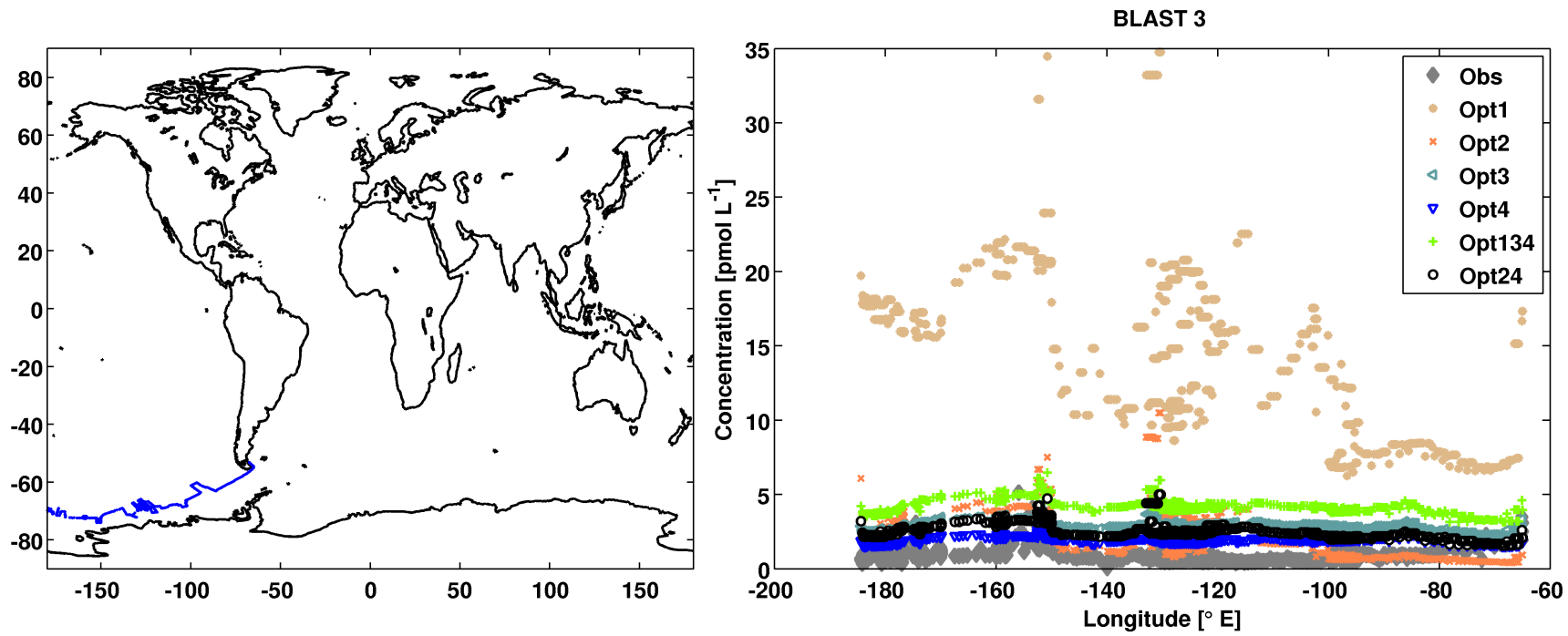

Figure S15 Observations are from the Nathaniel B. Palmer cruise BLAST 3, 22.02.-07.04.1996 (Butler et al., 2007) as listed in the SI of (Ziska et al., 2013). Values are shown only where the model ocean is deeper than $200 \mathrm{~m}$.
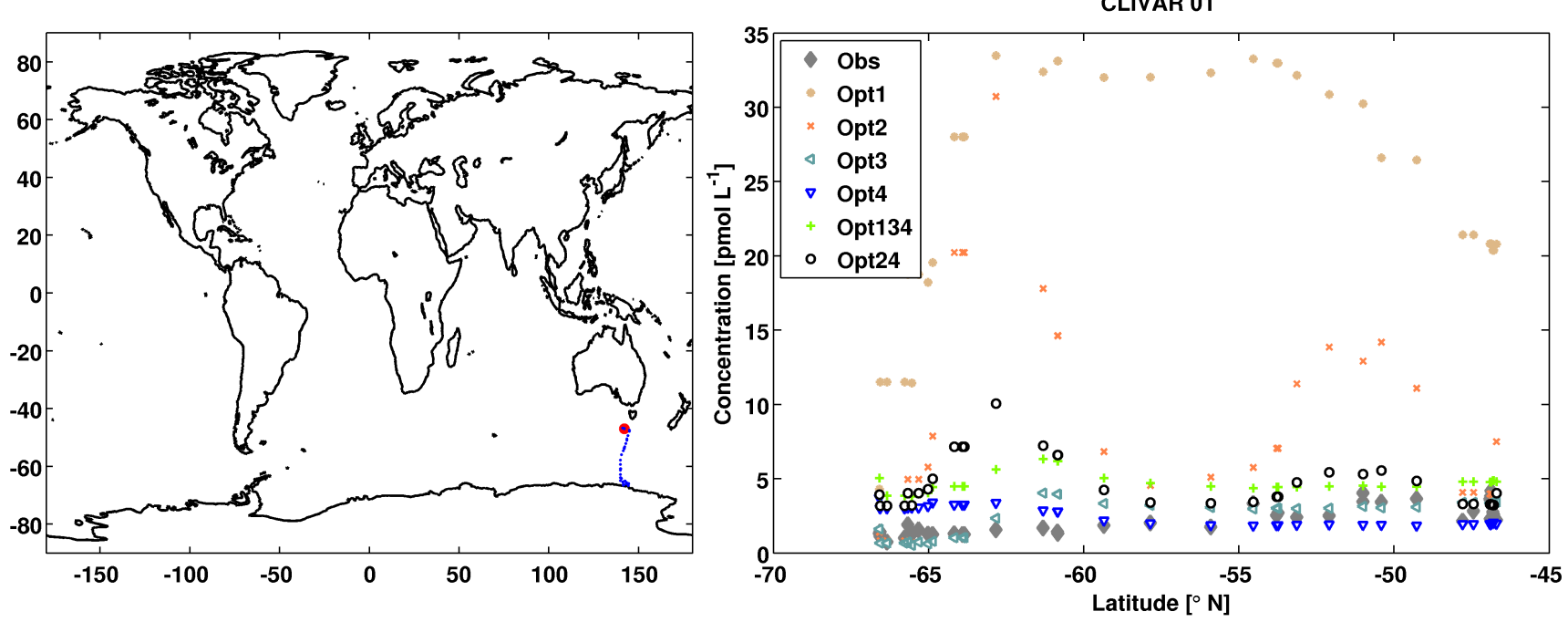

Figure S16 Observations are from the Aurora Australis cruise CLIVAR 01, 29.10.-13.12. 2001 (Butler et al., 2007) as listed in the SI of (Ziska et al., 2013). Values are shown only where the model ocean is deeper than $200 \mathrm{~m}$. 
SAMS northen seas program (JR75)
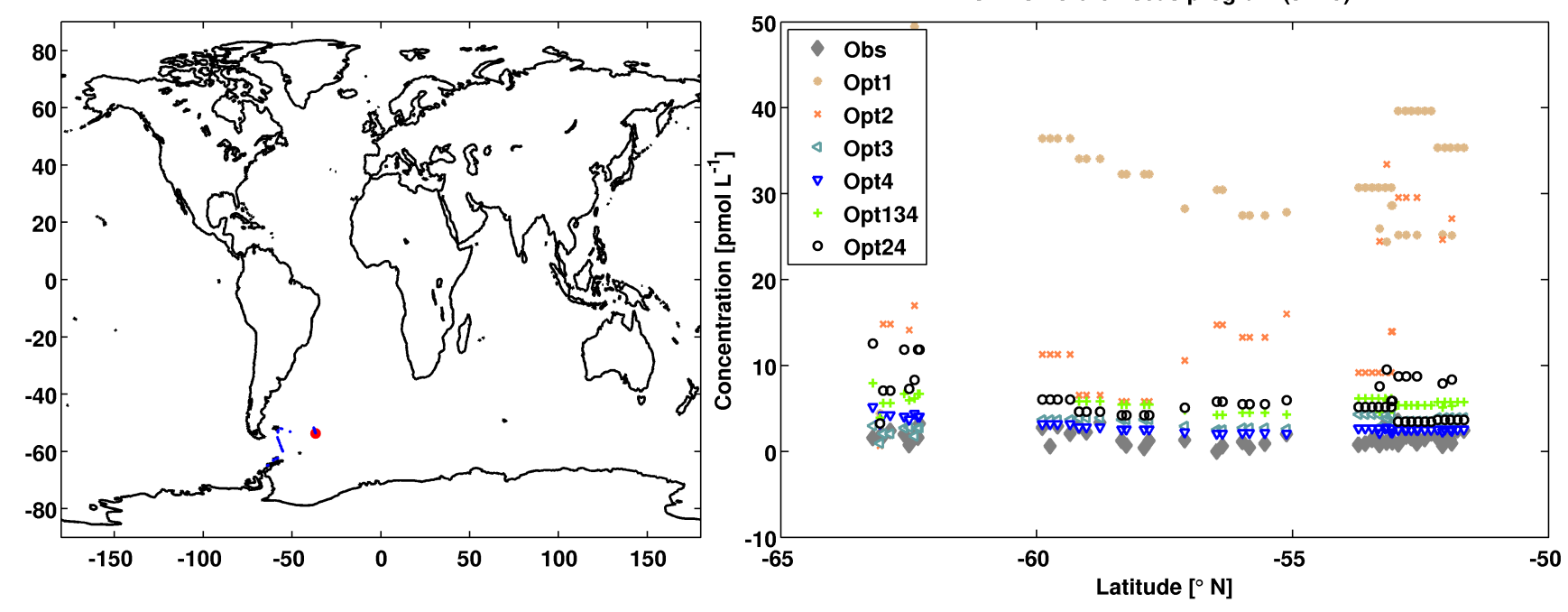

Figure S17 Observations are from the James Clark Ross cruise SAMS northen seas program (JR75) in November 2004 as listed in the SI of (Ziska et al., 2013). Values are shown only where the model ocean is deeper than $200 \mathrm{~m}$.
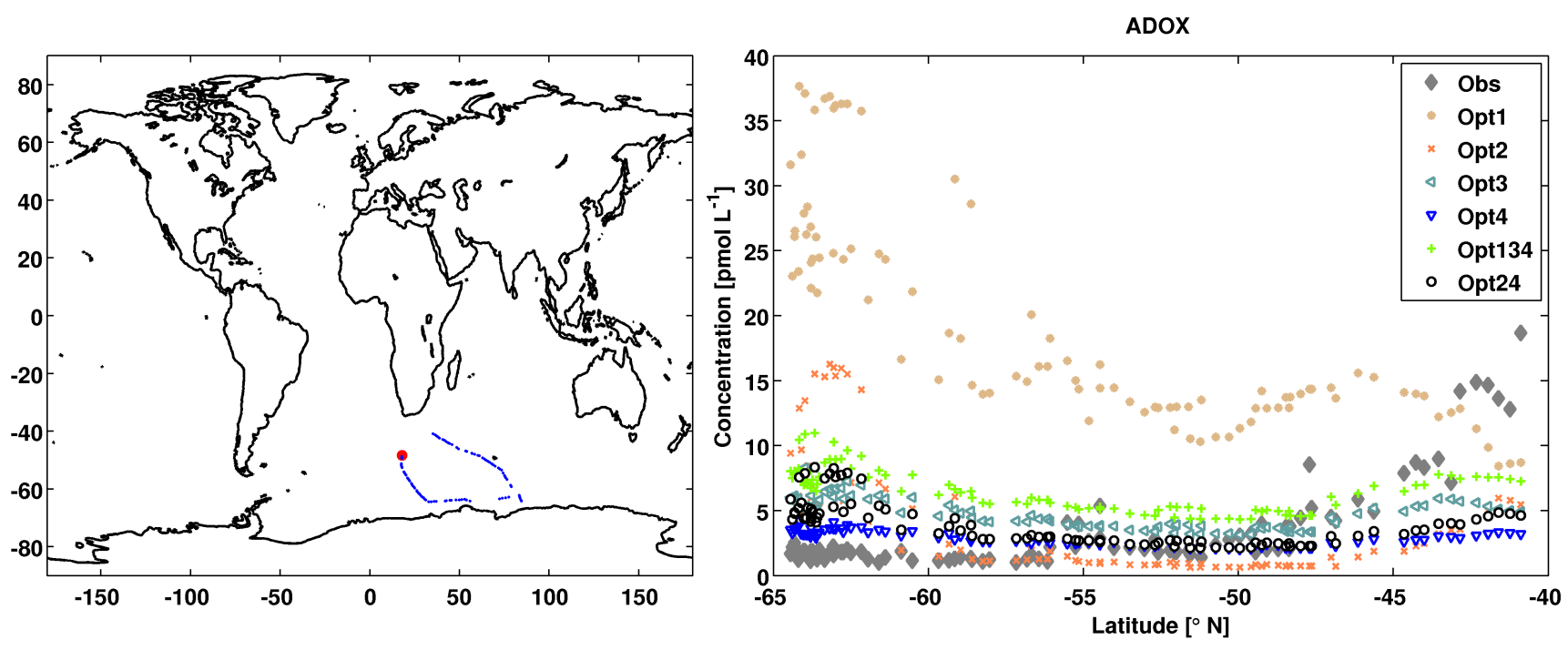

Figure S18 Observations are from the RRS Discovery (DISCO 200) cruise ADOX (Atlantic Deep Outflow Experiment) in February 1993 (Chuck et al., 2005) as listed in the SI of (Ziska et al., 2013). Values are shown only where the model ocean is deeper than $200 \mathrm{~m}$. 

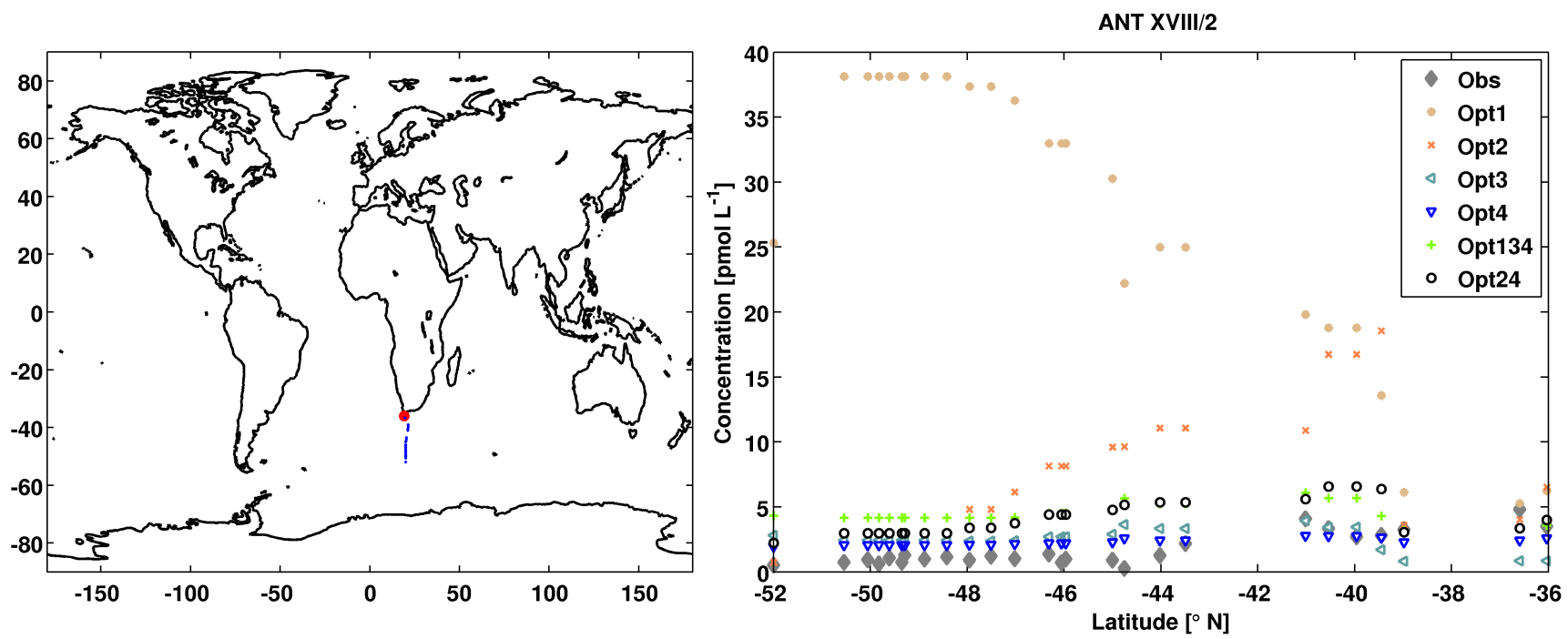

Figure S19 Observations are from the Polarstern cruise ANT XVIII/2 (Chuck et al., 2005) as listed in the SI of (Ziska et al., 2013). Values are shown only where the model ocean is deeper than $200 \mathrm{~m}$.
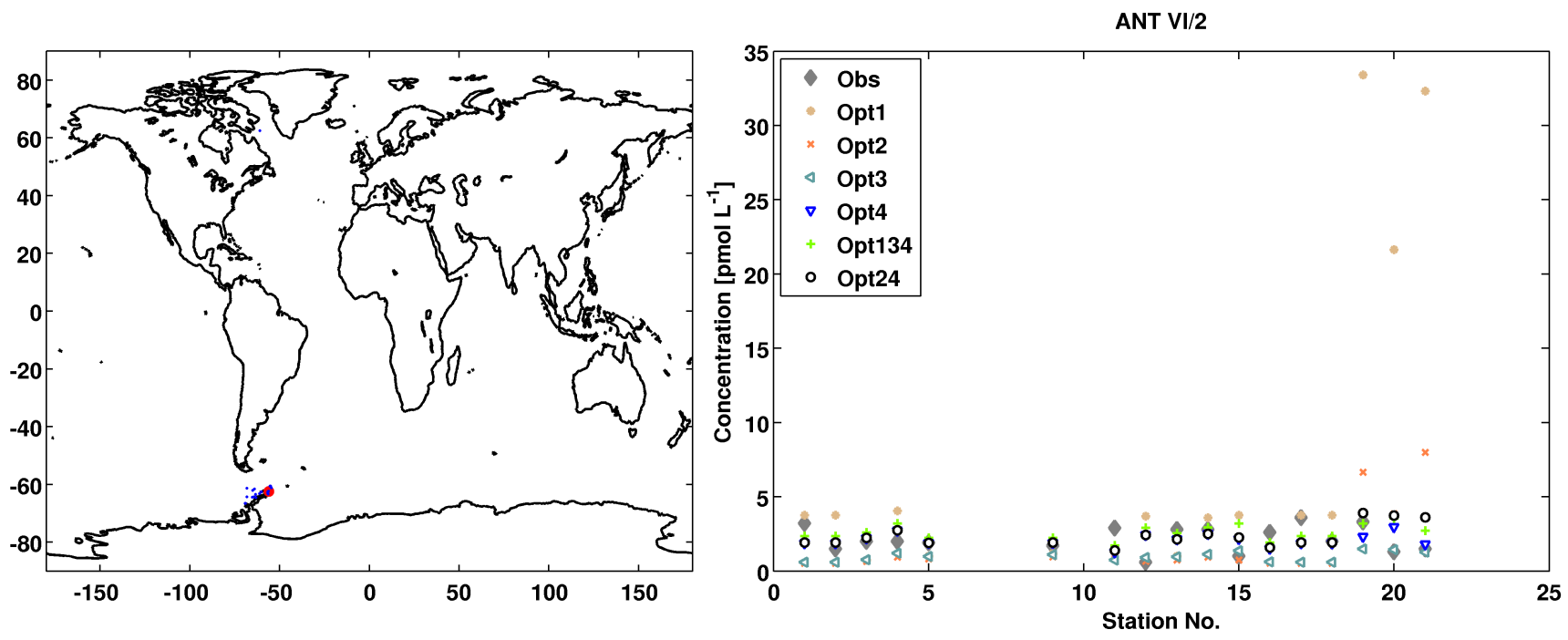

Figure S20 Observations are from the Polarstern cruise ANT VI/2 in October 1987 as listed in the SI of (Ziska et al., 2013). Values are shown only where the model ocean is deeper than $200 \mathrm{~m}$. 

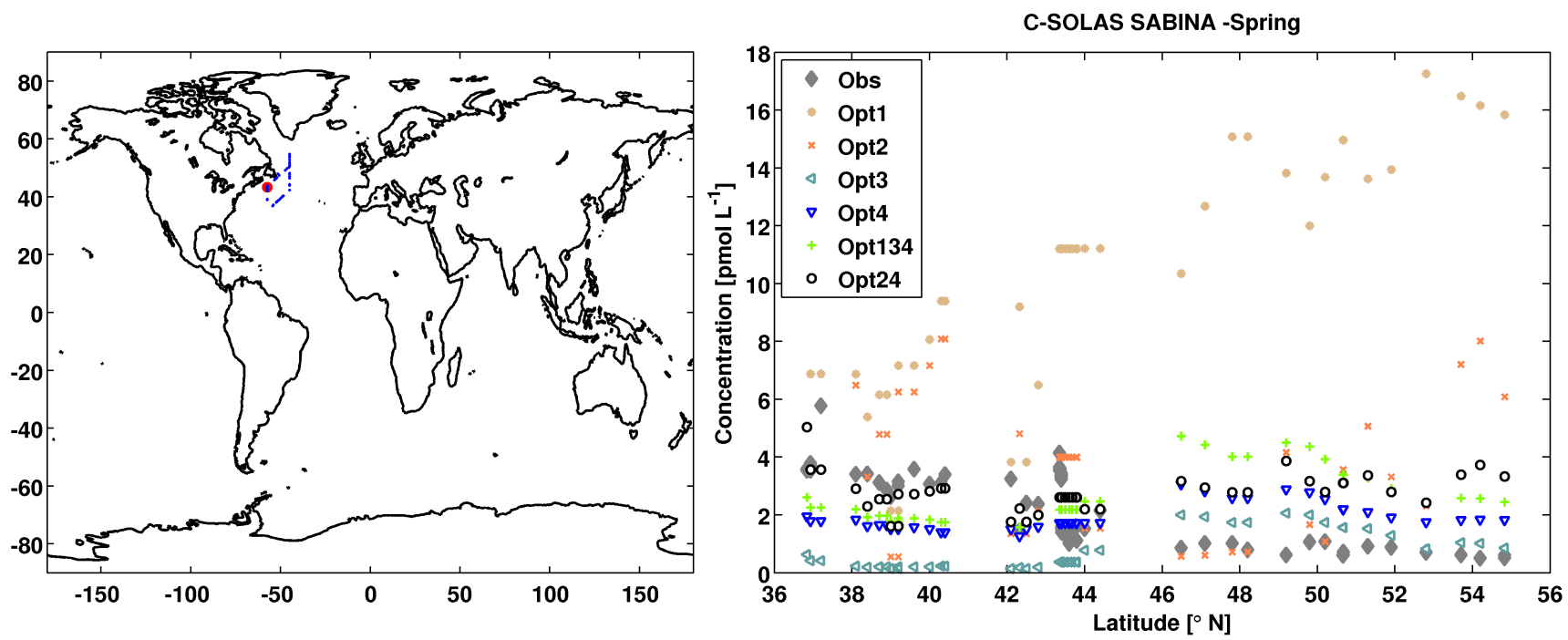

Figure S21 Observations are from the CCGS Martha L. Black cruise C-SOLAS SABINA in April 2003 (Wang et al., 2009) as listed in the SI of (Ziska et al., 2013). Values are shown only where the model ocean is deeper than $200 \mathrm{~m}$.
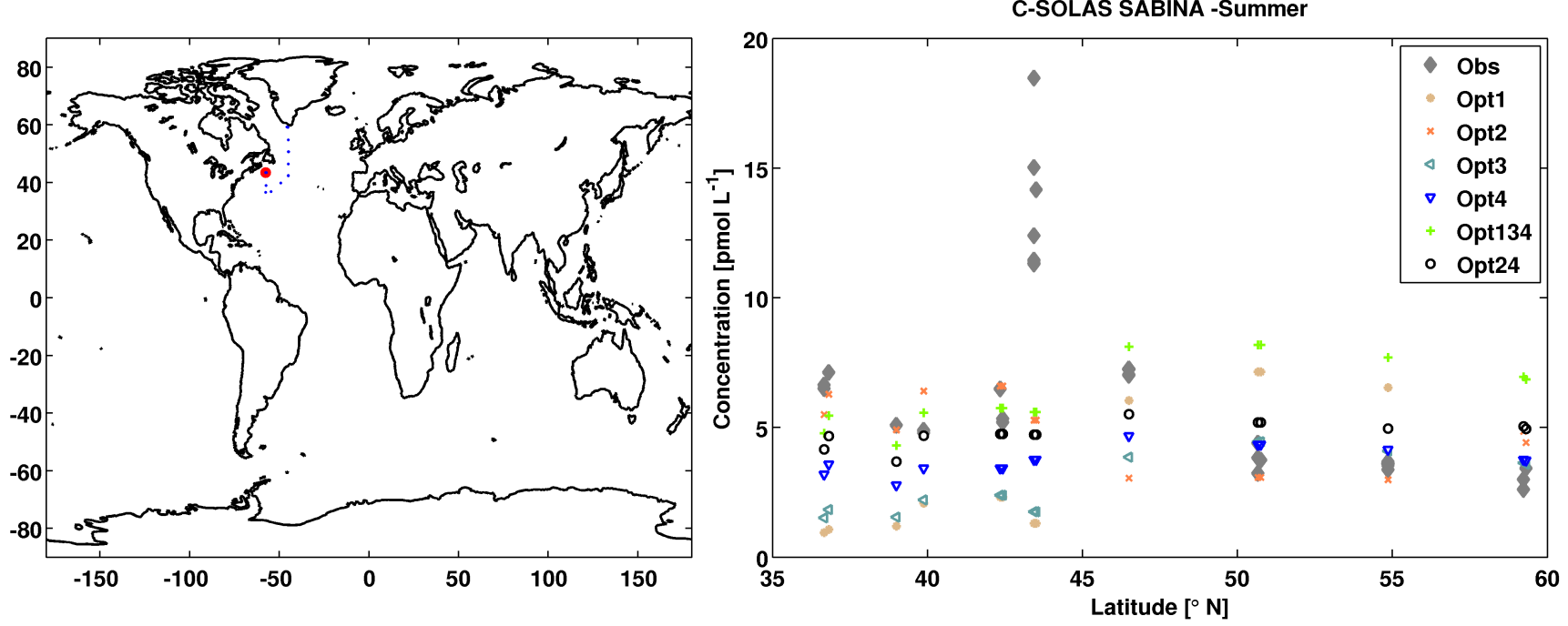

Figure S22 Observations are from the CCGS Martha L. Black cruise C-SOLAS SABINA in July 2003 (Wang et al., 2009) as listed in the SI of (Ziska et al., 2013). Values are shown only where the model ocean is deeper than $200 \mathrm{~m}$. 

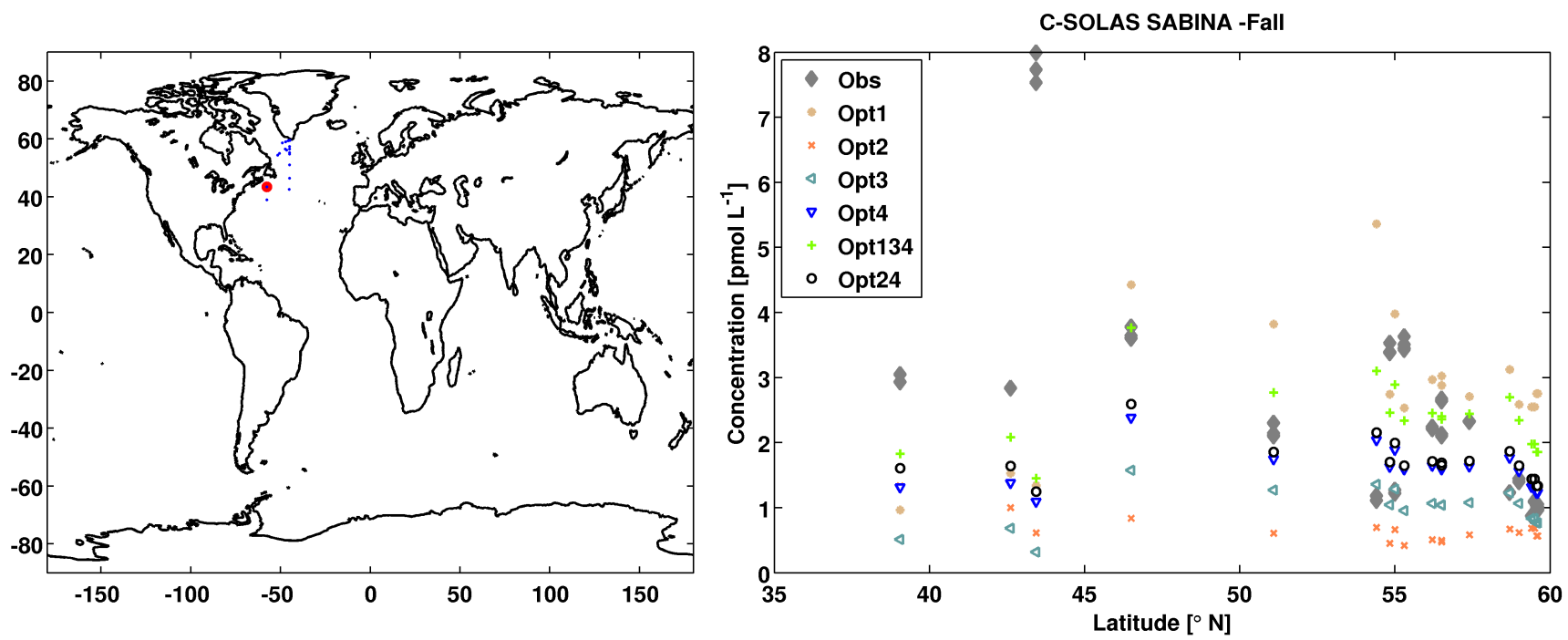

Figure S23 Observations are from the CCGS Martha L. Black cruise C-SOLAS SABINA in October 2003 (Wang et al., 2009 ) as listed in the SI of (Ziska et al., 2013). Values are shown only where the model ocean is deeper than $200 \mathrm{~m}$.
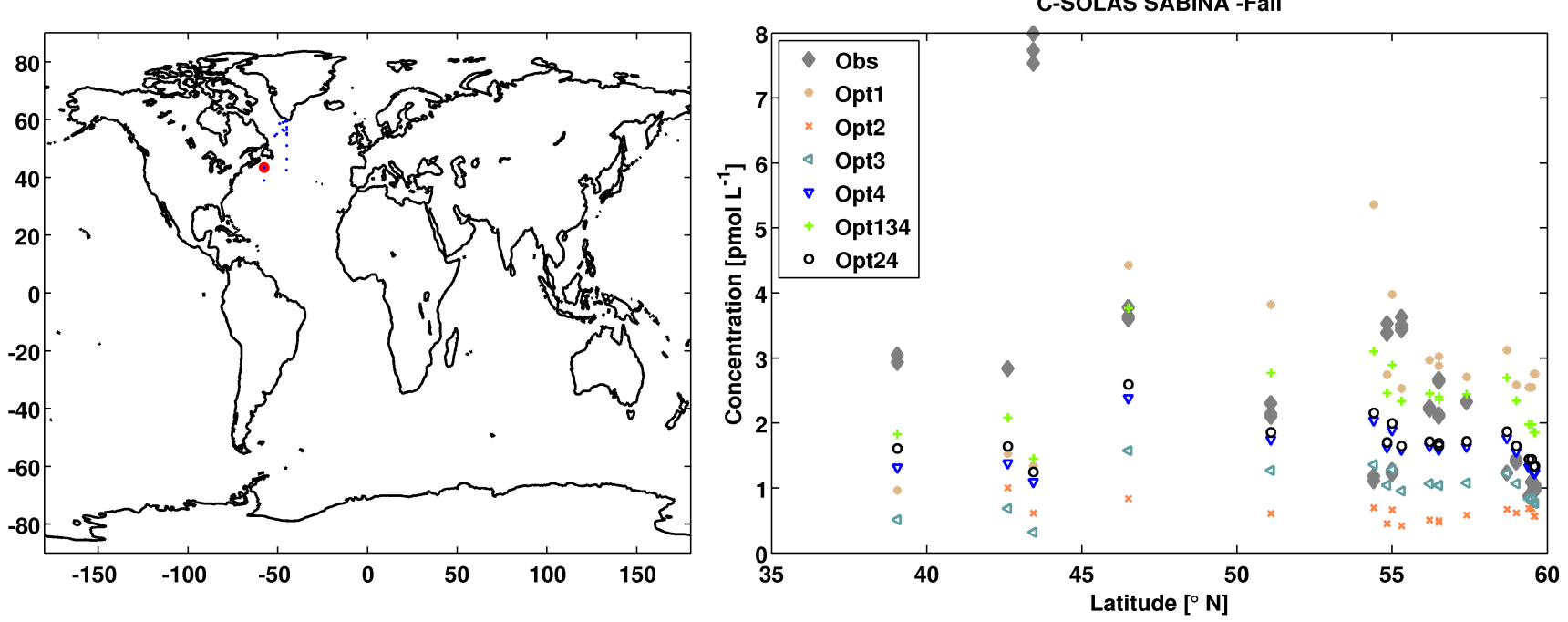

Figure S24 Observations are from the CCGS Tully C-SOLAS cruise in July 2003 (Moore and Wang, 2006) as listed in the SI of (Ziska et al., 2013). Values are shown only where the model ocean is deeper than $200 \mathrm{~m}$. 

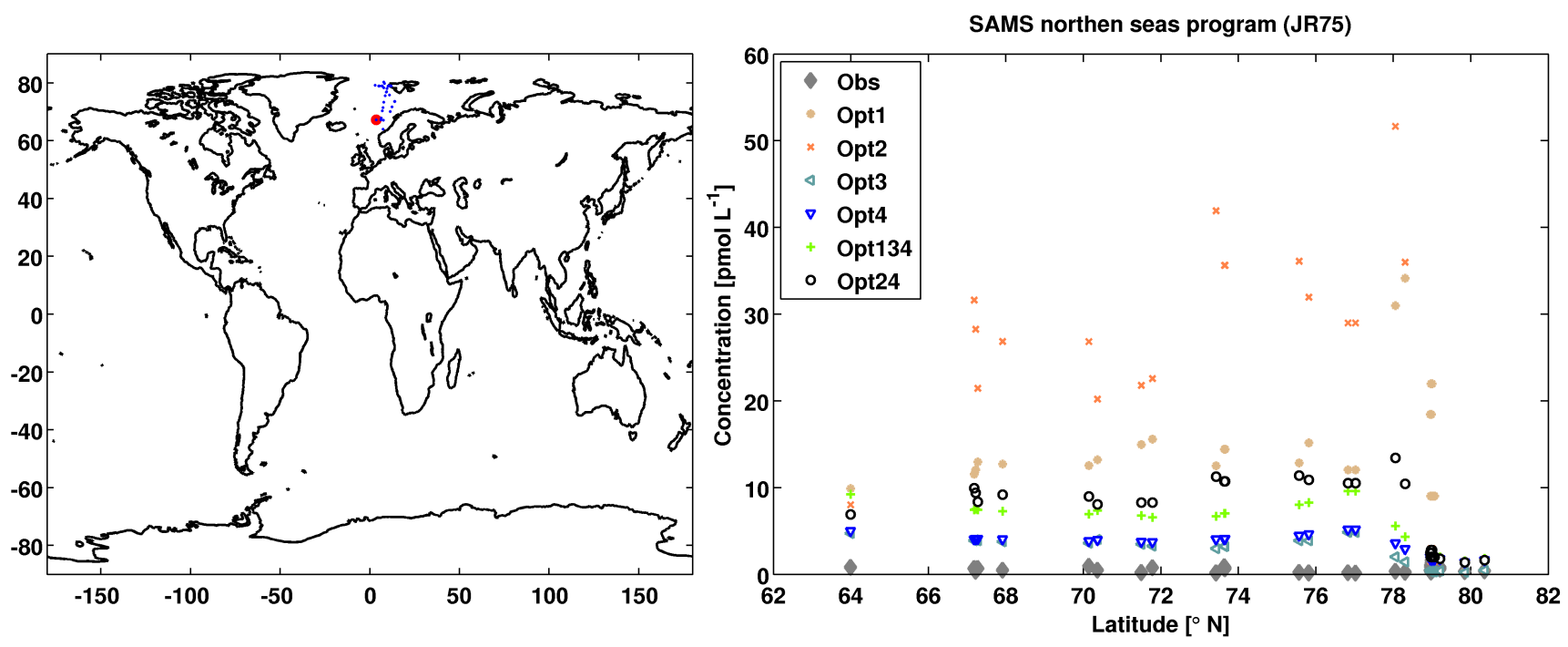

Figure S25 Observations are from the James Clark Ross cruise SAMS northen seas program (JR75) in June 2002 as listed in the SI of (Ziska et al., 2013). Values are shown only where the model ocean is deeper than $200 \mathrm{~m}$. 


\section{Sensitivity of $\mathrm{CH}_{3} \mathrm{I}$ concentrations towards atmospheric forcing and production rates}

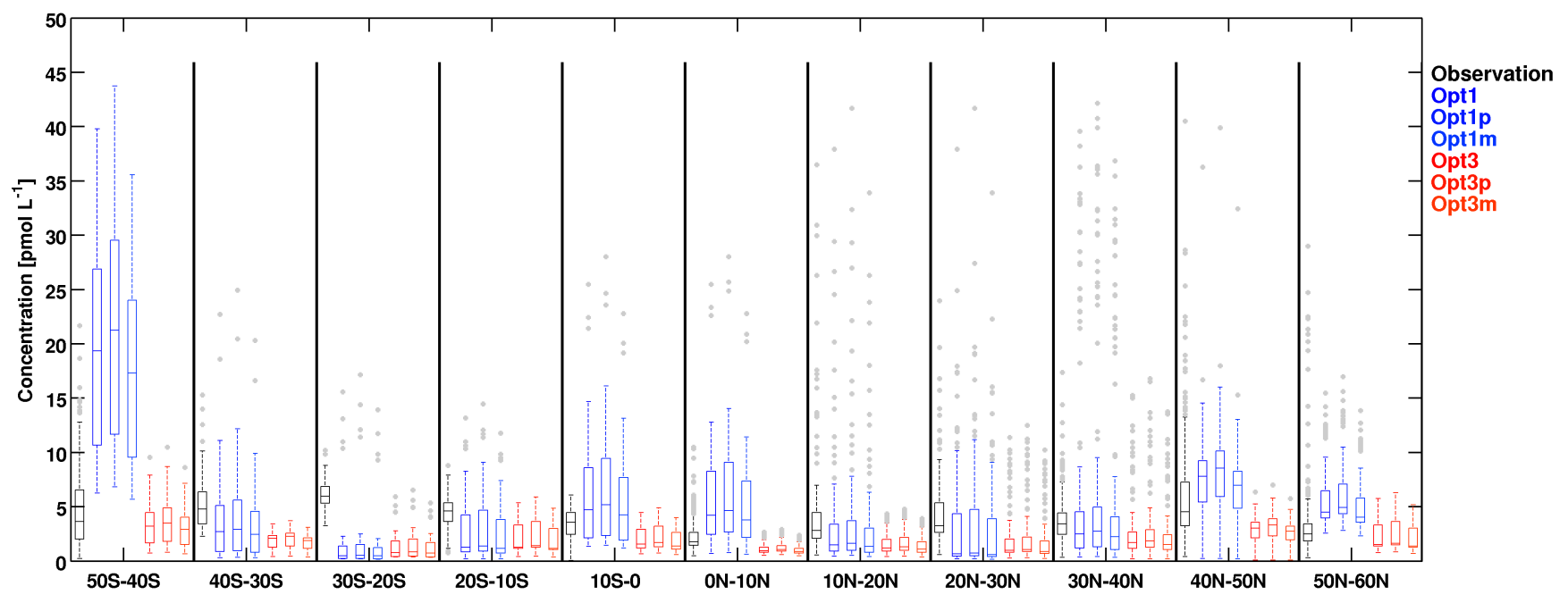

Figure S26 Box-Whisker plot of simulated and observed surface ocean $\mathrm{CH}_{3}$ I concentrations [pmol L-1]. Box widths are determined by the $25 \%$ and $75 \%$ percentile of data within each 10 degree latitude box, outliers (gray) are located outside 1.5 times the differences of the percentiles, the middle line of each box shows the median. Simulated concentrations are averaged over 1 degree boxes around the location of observations. 


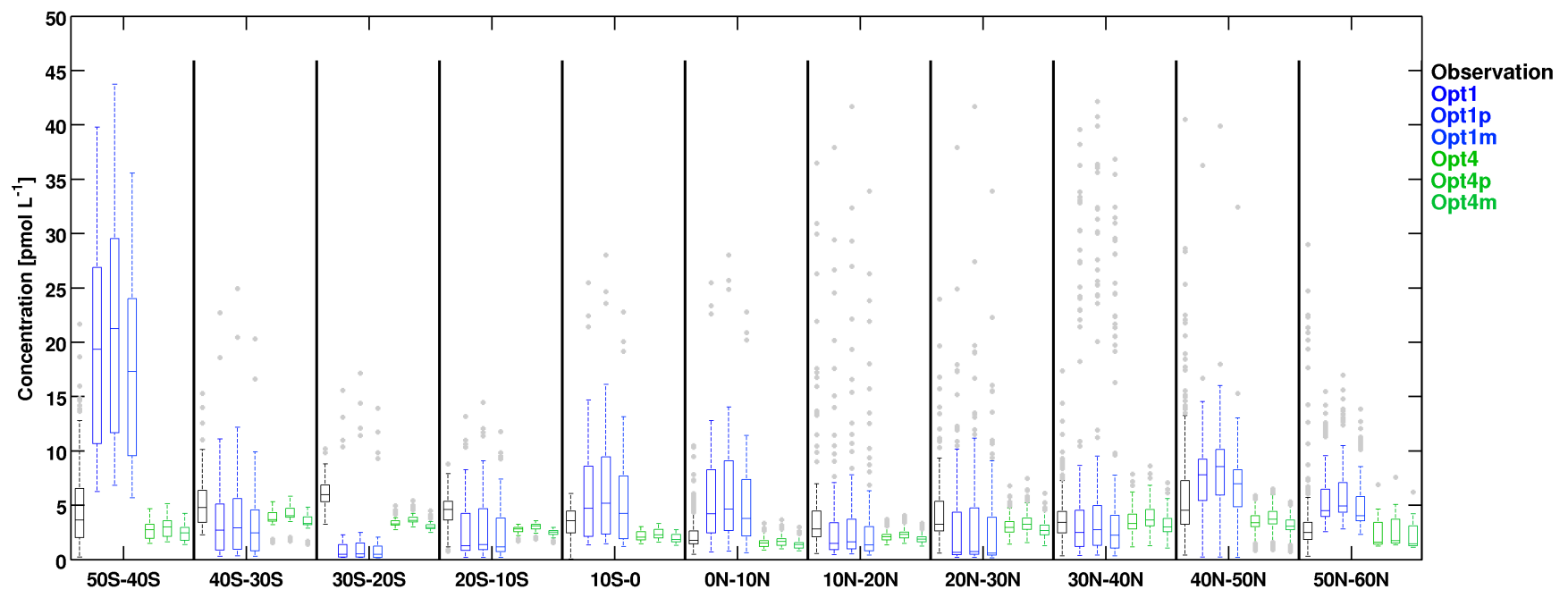

Figure S27 Box-Whisker plot of simulated and observed surface ocean $\mathrm{CH}_{3} \mathrm{I}$ concentrations [pmol L-1]. Box widths are determined by the $25 \%$ and $75 \%$ percentile of data within each 10 degree latitude box, outliers (gray) are located outside 1.5 times the differences of the percentiles, the middle line of each box shows the median. Simulated concentrations are averaged over 1 degree boxes around the location of observations. 

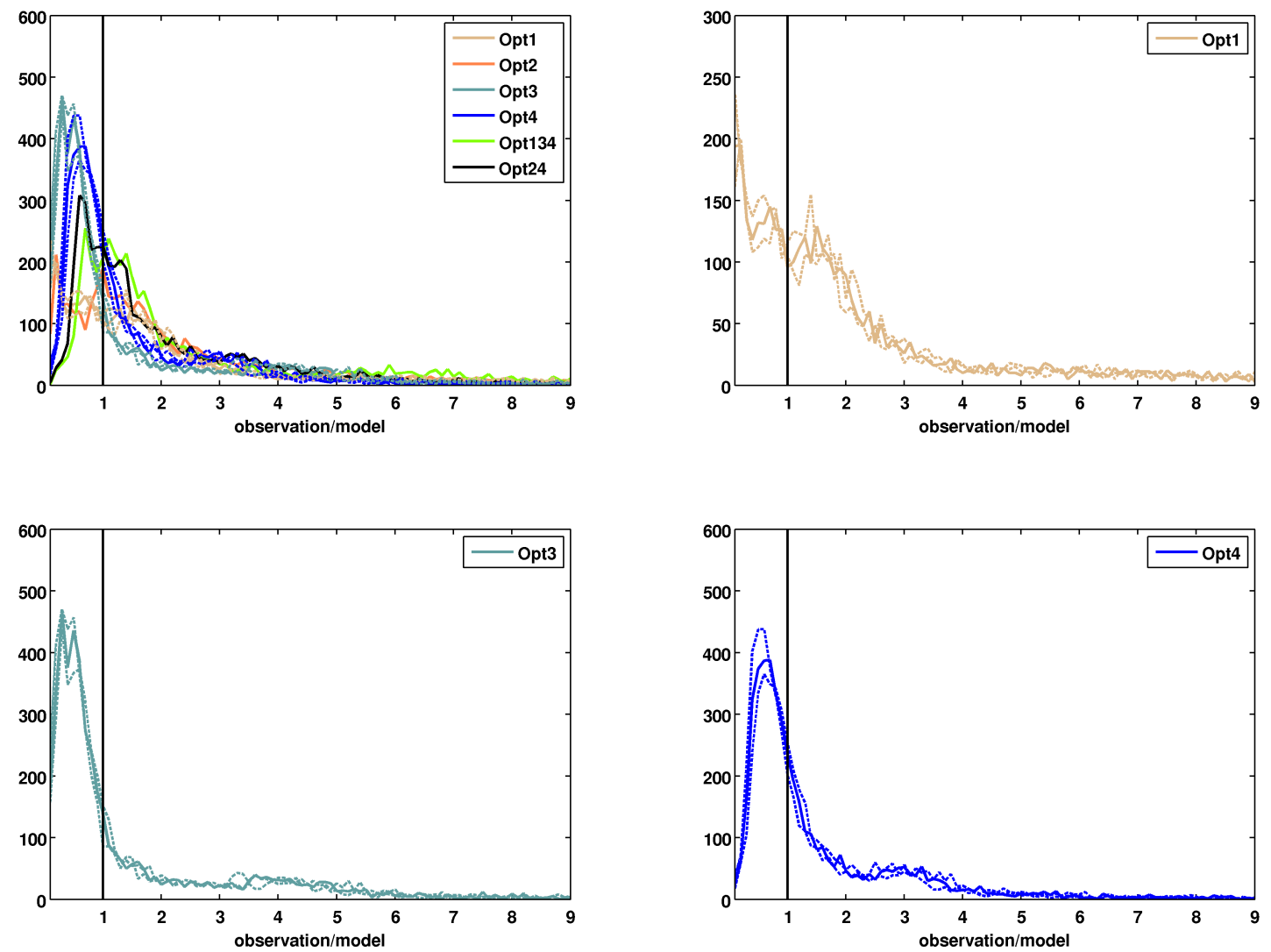

Figure S28 Histogram of the ratio between globally observed and simulated surface ocean methyl iodide concentrations (R=obs/model) for all original experiments and Opt $\{1,3,4\}\{\mathrm{p}, \mathrm{m}\}$ (upper left), Opt1 and Opt1p \& Opt1m (upper right), Opt3 \& Opt3p \& Opt3m (lower left), and Opt4 \& Opt4p \& Opt4m (lower right). 


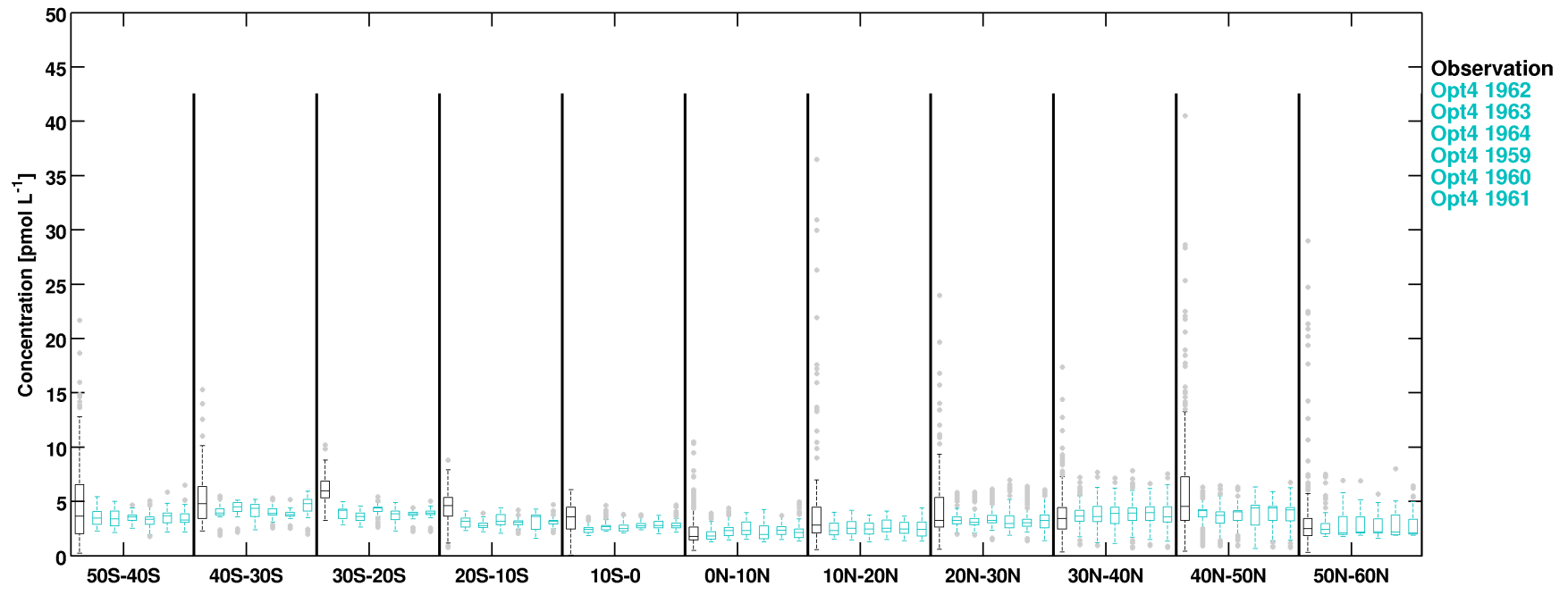

Figure S29 Box-Whisker plot of simulated and observed surface ocean $\mathrm{CH}_{3} \mathrm{I}$ concentrations [pmol L-1]. Box widths are determined by the $25 \%$ and $75 \%$ percentile of data within each 10 degree latitude box, outliers (gray) are located outside 1.5 times the differences of the percentiles, the middle line of each box shows the median. Simulated concentrations are averaged over 1 degree boxes around the location of observations. 


\section{Methyl iodide emissions}

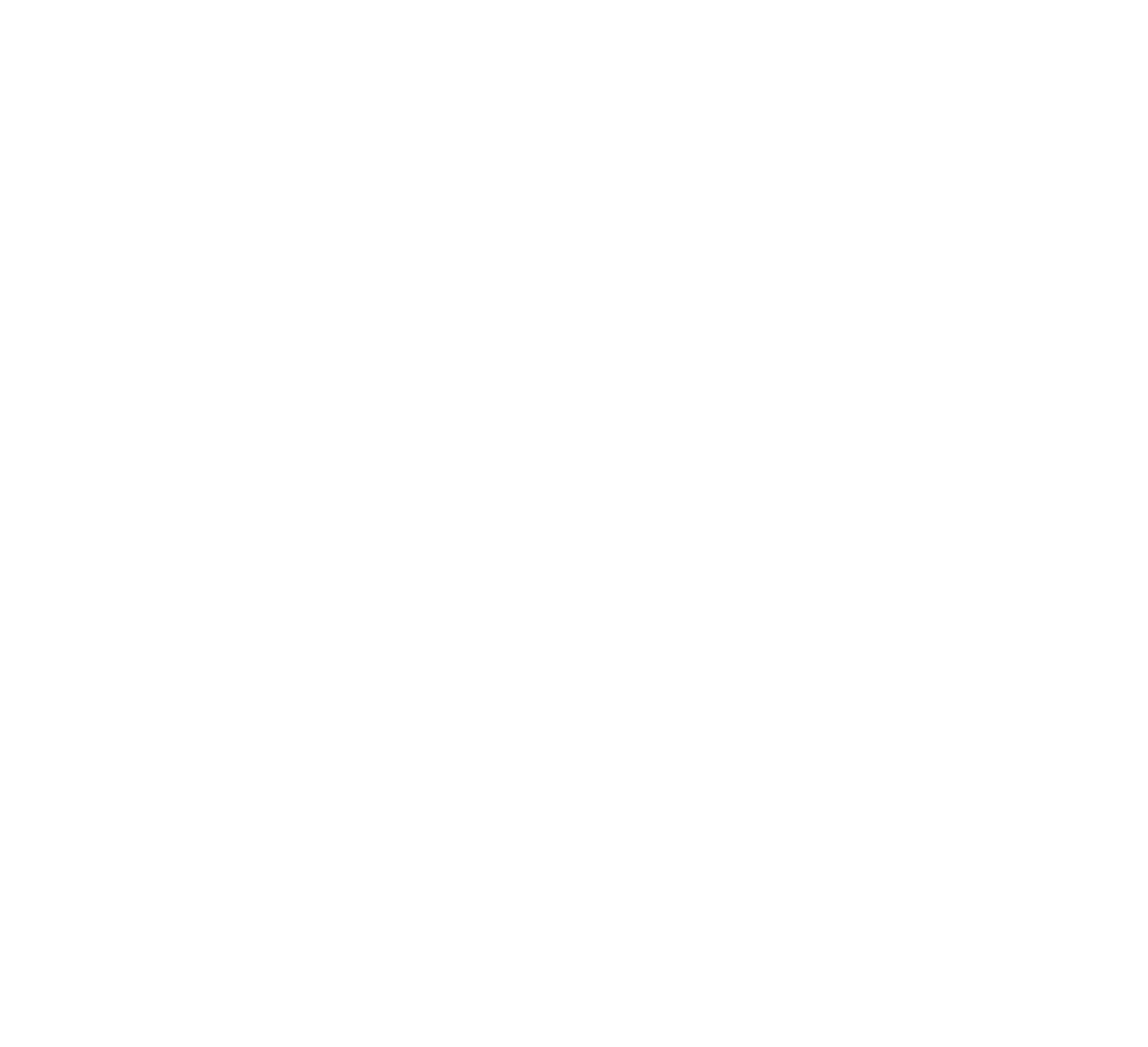

Figure S30 First 120 days of daily mean methyl iodide emissions in experiment Opt 4 [pmol m$\left.{ }^{-2} \mathrm{~h}^{-1}\right]$.

\section{References}

Abrahamsson, K., Bertilsson, S., Chierici, S., Fransson, A., Froneman, P., Lorén, A., and Pakhomov, E.: Variations of biochemical parameters alonga transect in the Southern Ocean, with special emphasis on volatile halogenated organic compounds, Deep-Sea Res. II, 51, 2745-2756, 2004.

Butler, J., King, D., Lobert, J., Montzka, S., Yvon-Lewis, S., Hall, B., Warwick, N., Mondell, D., Aydin, M., and Elkins, J.: Oceanic distributions and emissions of short-lived halocarbons, Glob. Biogeochem. Cyc., 21, 2007.

Chuck, A., Turner, S., and Liss, P.: Oceanic distributions and air-sea fluxes of biogenic halocarbons in the open ocean, J. Geophys. Res. - Oceans, 110, 1-12, 2005.

Jones, C., Hornsby, K., Sommariva, R., Dunk, R., Von Glasow, R., McFiggans, G., and Carpenter, L.: Quantifying the contribution of marine organic gases to atmospheric iodine, Geophysical Research Letters, 37, 2010. 
Moore, R. and Wang, L.: The influence of iron fertilization on the fluxes of methyl halides and isoprene from ocean to atmosphere in the SERIES experiment, Deep-Sea Research Part II: Topical Studies in Oceanography, 53, 2398-2409, 2006.

Schall, C., Heumann, K., and Kirst, G.: Biogenic volatile organoiodine and organobromine hydrocarbons in the Atlantic Ocean from $42 \mathrm{~N}$ to $72 \mathrm{~S}$, Fresenius' Journal of Analytical Chemistry, 359, 298-305, 1997.

Wang, L., Moore, R., and Cullen, J.: Methyl iodide in the NW Atlantic: Spatial and seasonal variation, Journal of Geophysical Research C: Oceans, 114, 2009.

Ziska, F., Quack, B., Abrahamsson, K., Archer, S. D., Atlas, E., Bell, T., Butler, J. H., Carpenter, L. J., Jones, C. E., Harris, N. R. P., Hepach, H., Heumann, K. G., Hughes, C., Kuss, J., Krüger, K., Liss, P., Moore, R. M., Orlikowska, A., Raimund, S., Reeves, C. E., Reifenhäuser, W., Robinson, A. D., Schall, C., Tanhua, T., Tegtmeier, S., Turner, S., Wang, L., Wallace, D., Williams, J., Yamamoto, H., Yvon-Lewis, S., and Yokouchi, Y.: Global sea-to-air flux climatology for bromoform, dibromomethane and methyl iodide, Atmospheric Chemistry and Physics, 13, 8915-8934, doi:10.5194/acp-13-8915-2013, 2013. 